\title{
Dinâmica do controle químico de Phakopsora pachyrhizi em plantas de soja submetidas a diferentes regimes hídricos
}

\section{Dynamics of fungicide in chemical control of Phakopsora pachyrhizi in soybean plants subjected to different water regimes}

\author{
Marlon Tagliapietra Stefanello ${ }^{1 *}$, Leandro Nascimento Marques', Felipe Frigo Pinto', \\ Juliano Perlin de Ramos ${ }^{1}$, Pedro Ceretta Cadore ${ }^{2}$, Ricardo Silveiro Balardin ${ }^{2}$
}

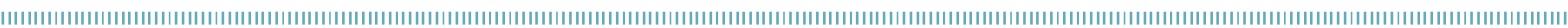

RESUMO: Objetivou-se com este trabalho avaliar a dinâmica do controle químico de Phakopsora pachyrhizi em plantas de soja submetidas a diferentes regimes hídricos. O experimento foi conduzido na área experimental do Instituto Phytus, no município de Itaara, região central do Rio Grande do Sul, na safra 2012/2013. O delineamento experimental utilizado foi inteiramente casualizado, com quatro repetiçōes, em arranjo fatorial ( $2 \times 6)$. O fator $A$ foi composto por dois regimes hídricos: 1) déficit hídrico (50-60\% da capacidade de campo); 2) sem déficit hídrico (90-100\% da capacidade de campo). O fator $\mathrm{B}$ consistiu em quatro intervalos de tempo entre a aplicaçáo de fungicidas e a simulação de chuva (0, 30, 60 e $120 \mathrm{~min})$, uma testemunha com aplicação sem chuva e mais uma testemunha sem aplicação de fungicida. Na aplicação foram utilizados os ingredientes ativos trifloxistrobina + protioconazol $\left(60,0+70,0\right.$ g i.a.ha $\left.{ }^{-1}\right)$ com adiçáo de Aureo ${ }^{\circledR}$ na dose de 0,375 L.p.c ha ${ }^{-1}$. Os parâmetros avaliados foram o tempo decorrido entre a aplicação e o surgimento da primeira pústula de ferrugem asiática, a severidade da doença, a produtividade e a massa de grãos. Verificou-se que a aplicação de fungicida em plantas sob déficit hídrico proporciona o maior número de dias para o aparecimento da primeira pústula. A simulação de chuva tem grande efeito na remoção de fungicidas independentemente do regime hídrico. O controle de P. pachyrhizi em plantas sob déficit hídrico foi eficaz, resultando em incrementos de produtividade.

PALAVRAS-CHAVE: chuva simulada; controle químico; ferrugem asiática da soja; déficit hídrico; residual de controle.

\begin{abstract}
The objective of this study was to evaluate the dynamics of chemical control of Phakopsora pachyrhizi in soybean plants subjected to different water regimes. The experiment was conducted in the experimental area of Phytus Institute, in Itaara city, central region of Rio Grande do Sul, in $2012 / 2013$ harvest. The experimental design was completely randomized, with four replications in a factorial arrangement (2x6). The first factor was composed of two water regimes: 1) water deficit (50-60\% of field capacity); 2) no water deficit (90-100\% of field capacity). The B factor was four time intervals between fungicide application and rainfall simulation $(0,30$, 60 and $120 \mathrm{~min}$ ), a witness to application without rain and a control without fungicide application. In application the active ingredients trifloxystrobin + prothioconazole $(60.0+70.0 \mathrm{~g}$ i.a.ha-1) with the addition of Aureo ${ }^{\circledR}$ at a dose of $0.375 \mathrm{Lpc} \mathrm{ha}^{-1}$ were used. The parameters evaluated were the number of days until the first pustule preview of Asian rust, disease severity, yield and grain yield. It was found that the fungicide application in plants under water deficit provides the greatest number of days until the first pustule preview. A rainfall simulation has great effect in removing fungicides no matter the water regime. The control of $P$. pachyrhizi in plants under water deficit was effective, resulting in increased productivity.
\end{abstract}

KEYWORDS: simulated rainfall; chemical control; Asian soybean rust; water deficit; residual control.

\footnotetext{
'Programa de Pós-Graduação em Agronomia; Centro de Ciências Rurais (CCR); Universidade Federal de Santa Maria (UFSM) - Santa Maria (RS), Brasil. 2Departamento de Defesa Fitossanitária; CCR; UFSM - Santa Maria (RS), Brasil.

*Autor correspondente: marlonstefanello@gmail.com

Recebido em: 16/09/2014. Aceito em: 31/08/2016
} 


\section{INTRODUÇÃO}

Nas últimas décadas, o uso de fungicidas na agricultura tornou-se fator crucial para o controle efetivo de doenças em plantas, uma vez que infecçôes fúngicas levam à redução de produtividade de cultivos em todo o mundo. No entanto, a ferrugem asiática da soja causada pelo fungo Phakopsora pachyrhizi vem se destacando nesse cenário, pois o molhamento foliar contínuo, promovido pela chuva ou por orvalho e sob condiçôes ótimas de temperatura, favorece o rápido estabelecimento e o desenvolvimento desse patógeno.

A resistência genética, considerada um dos métodos culturais mais adequados no manejo de doenças, para patógenos biotróficos é de difícil obtenção e, quando usada, apresenta-se pouco duradoura em função da variabilidade genética e do surgimento de novas raças. Dessa forma, o controle químico com fungicidas tornou-se o principal meio de controle desse tipo de patógeno amparado por outras práticas como nutrição, época de semeadura, espaçamento e vazio sanitário.

Além das perdas atribuídas exclusivamente às doenças, sáo relatadas perdas por ocorrência de adversidades climáticas como a seca. A imprevisibilidade das variaçôes climáticas tanto de chuvas como de déficit hídrico tornou-se elemento de preocupação no controle de doenças, sobretudo pela limitaçấo de estudos que explicam o comportamento das aplicaçóes fungicidas ou mesmo da interação dos produtos aplicados em parte aérea em plantas sob estresse.

$\mathrm{Na}$ condição de déficit hídrico a planta desenvolve mecanismos de defesa bioquímicos e estruturas pós-formadas em resposta ao tratamento com agentes abióticos (BONALDO et al., 2005; CAVALCANTI et al., 2005), proporcionando resistência à desidratação da planta. Essas alteraçôes morfofisiológicas e bioquímicas podem conferir diferentes respostas nas aplicaçôes quanto à difusão do fungicida em folhas, bem como seus efeitos na patogenicidade de fungos em plantas submetidas a essas condiçóes.

$\mathrm{Na}$ tomada de decisão para aplicações fungicidas sobre plantas em diferentes regimes hídricos, o conhecimento do comportamento das aplicaçôes nessas condiçôes é fundamental para a obtençáo de um manejo sustentável em busca de elevadas produtividades, no entanto poucos são os trabalhos na literatura que relacionam aplicaçôes de fungicidas em plantas sob déficit hídrico.

Com base no exposto, o experimento teve como objetivo avaliar a dinâmica do controle químico de $P$. pachyrhizi em plantas de soja submetidas a diferentes regimes hídricos.

\section{MATERIAL E MÉTODOS}

O experimento foi conduzido em casa de vegetaçáo durante o ano agrícola 2012/2013 na estaçáo experimental do Instituto Phytus, em Itaara (RS), latitude $29^{\circ} 35^{\prime} 08,5^{\prime}$ 'S, longitude $53^{\circ} 48^{\prime} 28,8^{\prime \prime} \mathrm{O}$ e altitude de $447 \mathrm{~m}$.
As condiçóes climáticas na casa de vegetaçáo foram parcialmente controladas: a temperatura por meio de exaustores, e a umidade relativa do ar mantida por um sistema de nebulização computadorizado. A temperatura do ar durante a condução do experimento variou de $16^{\circ}$ a $29^{\circ} \mathrm{C}$, e a umidade relativa do ar, entre 65 e $90 \%$.

Utilizou-se delineamento experimental inteiramente casualizado, com quatro repetições, em arranjo fatorial $(2 \times 6)$. O fator A foi composto de dois regimes hídricos:

1. déficit hídrico (50-60\% da capacidade de campo);

2. sem déficit hídrico (90-100\% da capacidade de campo).

$\mathrm{O}$ fator $\mathrm{B}$ consistiu em quatro intervalos de tempo entre a aplicação de fungicidas e a simulação de chuva $(0,30,60$ e $120 \mathrm{~min}$ ), uma testemunha com aplicação sem chuva e mais uma testemunha sem aplicação de fungicida.

A deficiência hídrica foi estabelecida por um período de 32 dias, até a aplicação dos tratamentos. Decorridos sete dias da aplicação dos tratamentos, a irrigação foi reestabelecida, e mantiveram-se as plantas de soja em condiçôes favoráveis até o fim do ciclo, ou seja, na capacidade de campo de $90-100 \%$.

Para a determinação da quantidade de água a ser colocada nos tratamentos, o substrato preparado foi levado para a estufa a $50^{\circ} \mathrm{C}$ com circulação de ar forçado por um mês para a obtenção do substrato seco. Uma amostra do substrato foi encaminhada para o Laboratório de Física dos Solos da Universidade Federal de Santa Maria (UFSM) a fim de estabelecer a capacidade de campo. Por intermédio desse valor, calculou-se a quantidade de água necessária para caracterizar os diferentes regimes hídricos em uma quantidade de solo alocada em vasos de $5 \mathrm{~kg}$. O controle da irrigação foi realizado manualmente pelo método de pesagem de vasos. As irrigaçóes aconteceram todos os dias mediante a diferença de peso dos vasos, sendo a umidade do solo elevada até a capacidade de campo desejada (CARVAlHo, 2001).

Em ambos os regimes hídricos foi adicionado, além dos valores de água, o peso da planta existente no vaso. Para isso, a cada cinco dias se obteve o peso médio de uma planta.

Após o período de restriçáo hídrica para os tratamentos considerados, foi feita a aplicaçâo do fungicida quando as plantas se encontravam no estádio R4 (FeHr; Caviness, 1977). Foi utilizada a mistura dos ingredientes ativos trifloxistrobina + protioconazol $\left(60+70\right.$ g i.a.ha $\left.{ }^{-1}\right)$ com adiçấo de Aureo $^{\oplus}$ na dose de 0,375 L.p.c.ha ${ }^{-1}$. Definiu-se a dose do produto conforme recomendaçáo do fabricante.

A aplicação foi de caráter preventivo, utilizando-se pulverizador costal dotado de quatro pontas de pulverização, pressurizado com $\mathrm{CO}_{2}$ e calibrado para taxa de aplicação de $150 \mathrm{~L} \mathrm{ha}^{-1}$. Usou-se o espectro de gota fina.

Depois da aplicaçáo do fungicida, foi simulada chuva nos intervalos de 0, 30, 60 e 120 minutos após a aplicação, além de uma testemunha com fungicida e sem chuva. Para a simulação de chuva foi empregada metodologia desenvolvida e validada 
por Debortoli (2008). O equipamento do referido autor é adequado para reproduzir as características de chuva natural em precipitaçáo simulada. Subentende-se por essa metodologia que o depósito do fungicida não penetrado nos folíolos seja removido pela chuva. Posteriormente à simulação de chuva, os vasos foram conduzidos para a casa de vegetaçáo, onde foram mantidos até o fim do experimento.

O estabelecimento da doença deu-se de maneira artificial, inoculando uredósporos de P. pachyrhizi 12 horas depois da aplicação do fungicida, de acordo com a metodologia proposta por Lenz (2010). Os esporos utilizados na inoculaçáo de P. pachyrhizi foram obtidos por intermédio da coleta manual de folhas de soja infectadas com o patógeno. Os esporos foram retirados das folhas utilizando água. A soluçáo entâo era filtrada e adicionava-se a ela espalhante adesivo (Tween $80-100 \mathrm{ppm}$ ).

A concentraçáo de esporos de $P$. pachyrhizi na soluçáo foi de aproximadamente $2 \times 10^{5}$ esporos $\mathrm{mL}^{-1}$, obtida por meio de contagem em hemacitômetro com auxílio de microscópio óptico dotado de aumento de 100 vezes. A inoculação foi feita à noite, com ajuda de uma pistola de micropintura depositando a solução com o inóculo em ambas as faces das folhas.

Decorridas 10 horas da inoculaçáo artificial, ao amanhecer, foram iniciadas as nebulizaçôes, programadas por um controlador eletrônico para execuçáo de turno de nebulização de $1 \mathrm{~min} /$ hora, mantendo-se assim condiçôes favoráveis ao desenvolvimento do fungo.

Dois dias após a inoculação das folhas de soja, foram realizadas avaliaçôes diárias, para visualização do aparecimento das primeiras pústulas. Foi considerada pústula quando era notável esporulação do patógeno. Nas avaliaçóes foram levados em conta o primeiro e o segundo trifólio de cada planta de cima para baixo devidamente marcados.

A severidade de $P$. pachyrhizi foi avaliada aos 30 dias em seguida à aplicação dos tratamentos fungicidas (30DAA). Para a determinaçáo da severidade, foram atribuídas notas visuais do percentual de área foliar com sintomas da doença em relaçáo à área sadia da folha mediante a escala proposta por Godor et al. (2006).

A produtividade das plantas de soja $\left(\mathrm{g} \mathrm{planta}^{-1}\right)$ e a massa de grão $\left(\mathrm{g}_{\text {grão }}{ }^{-1}\right)$ foram definidas ao término do ciclo das plantas. Os dados foram obtidos por intermédio da colheita e posterior debulha manual das vagens de cada planta de soja. No fim foram realizadas a pesagem total de grãos por planta e a pesagem da massa de grãos por grão, sendo ajustadas para umidade de $13 \%$.

Para a obtenção dos dados da massa de grão por grão, utilizaram-se os valores do peso total de grãos por planta já ajustados e posteriormente divididos pelo número total de grãos por planta.

Os dados alcançados foram submetidos à análise de variância (ANOVA) e as médias comparadas por meio do teste de Tukey a $1 \%$ de probabilidade de erro, com a utilização do pacote estatístico Assistat ${ }^{\circledast}$ versão 7.5 beta (Silva; Azevedo, 2002).

\section{RESULTADOS E DISCUSSÃO}

A análise de variância revelou interaçáo significativa entre os fatores analisados para as variáveis Número de Dias para Aparecimento da Primeira Pústula (NDAPP), severidade de P. pachyrhizi em folhas e produtividade de grãos (Figs. 1 a 3).

O NDAPP demonstra indiretamente a velocidade de penetração do fungicida nas aplicaçôes em diferentes intervalos de simulaçôes de chuva, exercendo influência na interaçáo fungicida/planta em aplicaçóes de parte aérea. Observa-se que quanto menor é o intervalo de tempo entre a aplicaçáo do fungicida e as simulaçóes de chuva, menor é o tempo para o aparecimento da primeira pústula (Fig. 1). Infere-se que pela chuva ocorre lavagem, e todo o fungicida ainda não penetrado no tecido foliar é removido.

Nota-se em plantas de soja sob condição favorável (sem déficit hídrico) que a simulação de chuva interferiu na retenção de produto na folha mesmo 120 minutos após a aplicação. Como consequência, pode-se dizer que o tratamento apresentou 1,75 dia a menos de residual químico para controle da doença do que o tratamento fungicida sem simulação de chuva. $\mathrm{Na}$ condição de deficiência hídrica, a simulação de chuva aos 120 minutos representou 2,25 dias a menos de residual de controle da doença em comparaçáo à testemunha com fungicida sem simulação de chuva. Deвortoli (2008), em estudo com o objetivo de avaliar o efeito da chuva sobre o residual de azoxistrobina + ciproconazol em sete cultivares de soja, notou que simulação de chuva 240 minutos após a aplicação do fungicida influenciou a taxa de penetraçáo do pesticida.

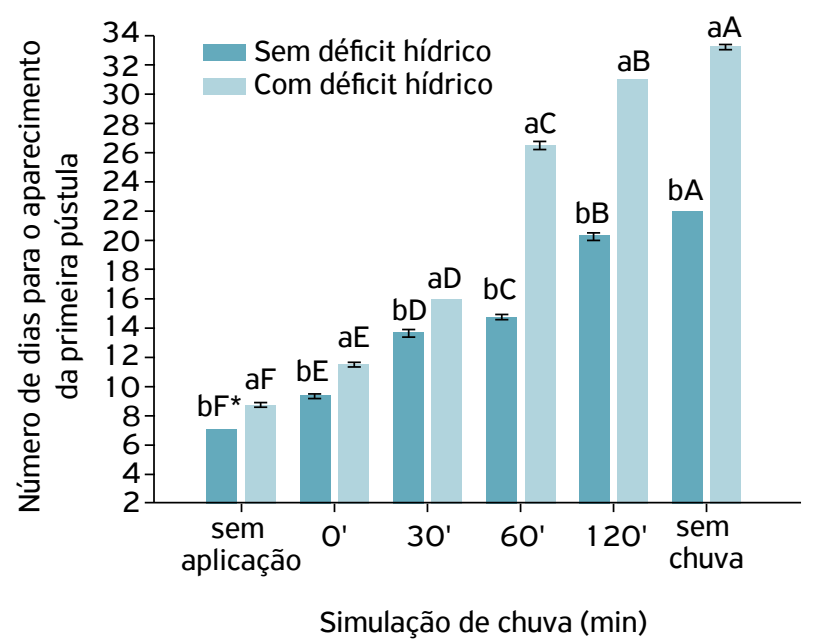

*Letras minúsculas: comparação de regimes hídricos em cada combinação de intervalos de simulação de chuva; letras maiúsculas: comparação de intervalos de simulação de chuva em cada combinação de regime hídrico; médias seguidas pelas mesmas letras minúsculas e maiúsculas não diferem estatisticamente entre si pelo teste de Tukey ao nível de $1 \%$ de probabilidade de erro; $\mathrm{CV}(\%)=1,84$.

Figura 1. Número de dias para o aparecimento da primeira pústula de Phakopsora pachyrhizi na interação entre regimes hídricos e intervalos de simulação de chuva após a aplicação de fungicidas. Itaara - RS, 2013. 
Mesmo com simulação de chuva 0 min depois da aplicação do fungicida, nota-se que há um percentual do ingrediente ativo que é rapidamente absorvido, independentemente do regime hídrico imposto às plantas. Isso é possível de inferir em função do atraso do aparecimento da primeira pústula de $P$. pachyrhizi em folhas que receberam fungicidas e tiveram simulação de chuva a 0 min após aplicação em comparação à testemunha sem fungicida.

Verificam-se nos resultados das Figuras 1 e 2 redução significativa na severidade de $P$. pachyrhizi e retardamento do aparecimento da primeira pústula em plantas sob déficit hídrico, quando comparada às plantas em condição favorável (sem déficit hídrico).

Pode-se observar que as plantas testemunhas sem fungicida sob déficit hídrico apresentaram a primeira pústula 1,75 dia a mais na comparaçáo com as plantas testemunhas em condições favoráveis. TAIZ; ZEIGER (2013) sugeriram que plantas em deficiência hídrica respondem contra a desidratação, por meio do espessamento da cutícula, para diminuir a transpiração, bem como pela penetração de patógenos. Segundo Paiva; Oliveira (2006), várias estratégias são desenvolvidas pelas plantas em déficit hídrico para reduzir a perda de água e otimizar o uso da pequena quantidade que ainda possa ser encontrada no solo.

A aplicação de fungicida sem simulação de chuva em plantas sob déficit hídrico representou 11,25 dias de atraso no aparecimento da primeira pústula e $1,8 \%$ de redução na severidade de $P$. pachyrhizi, em relação ao mesmo tratamento com plantas em condição favorável. Os dados sugerem que a

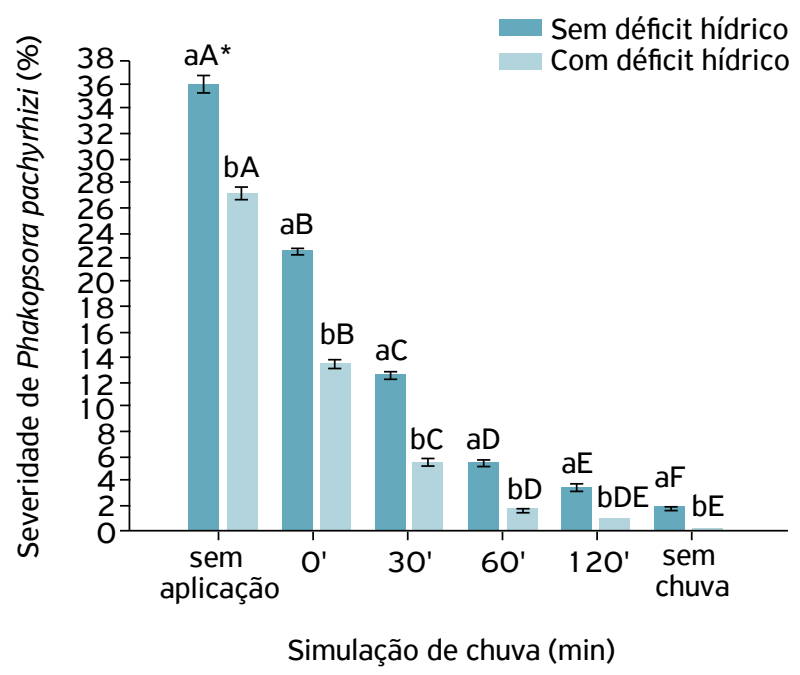

*Letras minúsculas: comparação de regimes hídricos em cada combinação de intervalos de simulação de chuva; letras maiúsculas: comparação de intervalos de simulação de chuva em cada combinação de regime hídrico; médias seguidas pelas mesmas letras minúsculas e maiúsculas não diferem estatisticamente entre si pelo teste de Tukey ao nível de $1 \%$ de probabilidade de erro; CV (\%) = 5,92.

Figura 2. Severidade de Phakopsora pachyrhizi (\%) na interação entre regimes hídricos e intervalos de simulação de chuva após a aplicação aos 30 dias após a aplicação. Itaara - RS, 2013. concentração de ativo fungicida na célula é maior em plantas sob déficit hídrico, por conta da diminuição do potencial hídrico das folhas e da turgescência, ainda que o ativo fungicida seja mais lentamente degradado em plantas sob déficit hídrico, em função da menor atividade fisiológica, da queda na condutância estomática e do fechamento dos estômatos (STUHFAUTh et al., 1990; OHASHi et al., 2006; Lei et al., 2006). Isso ajudaria a explicar a redução nos valores de severidade e o atraso no aparecimento das primeiras pústulas.

$\mathrm{Na}$ condição de estresse, a planta reduz a demanda por adenosina trifosfato (ATP) como consequência da reduçáo do crescimento e da fotossíntese (Flexas; Medrano, 2002), e, com isso, decresce a degradação do fungicida em plantas nessa condição.

Verifica-se na Figura 3 redução significativa na produtividade em plantas sob déficit hídrico, quando em comparação às plantas sem déficit hídrico. A falta de água no solo é extremamente prejudicial para a planta — pode limitar o potencial produtivo em diversas espécies (SANTos; Carlesso, 1998), bem como provocar menor crescimento durante o período vegetativo (Lobato et al., 2008) e promover o aborto de flores durante o período reprodutivo (Pimentel, 2004).

Em plantas sob condição favorável de água, constatou-se redução de produtividade pela aplicação do fungicida e simulação de chuva aos 30 minutos em comparação à aplicação sem chuva. Isso mostra a remoção do fungicida em folhas em períodos iniciais após a aplicação, que proporcionou expressivos valores de severidade da doença, resultando em redução na produção de grãos.

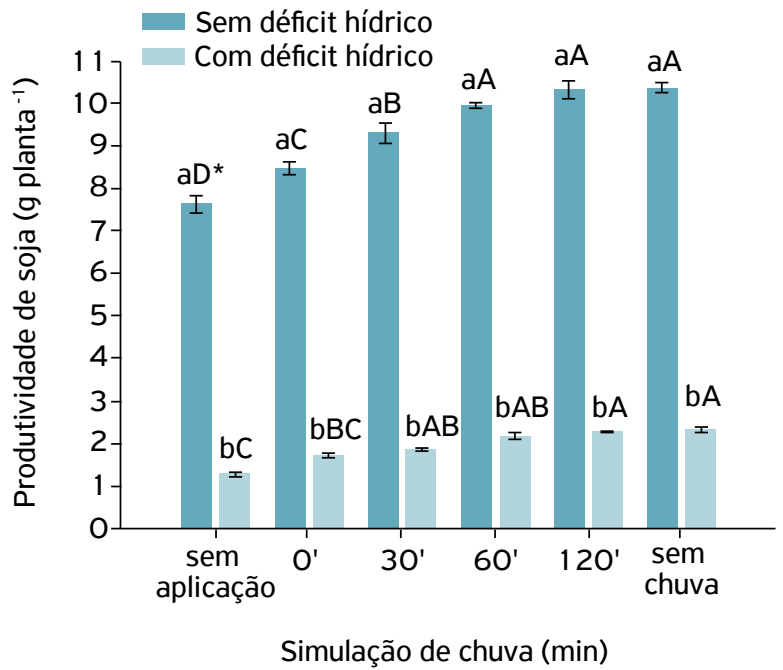

*Letras minúsculas: comparação de regimes hídricos em cada combinação de intervalos de simulação de chuva; letras maiúsculas: comparação de intervalos de simulação de chuva em cada combinação de regime hídrico; médias seguidas pelas mesmas letras minúsculas e maiúsculas não diferem estatisticamente entre si pelo teste de Tukey ao nível de $1 \%$ de probabilidade de erro; CV (\%): coeficiente de variação $=4,42$.

Figura 3. Produtividade de soja (g planta-1) na interação entre regimes hídricos e intervalos de simulação de chuva após a aplicação de fungicida. Itaara - RS, 2013. 
A aplicação do fungicida em plantas sob déficit hídrico sem simulação de chuva promoveu aumento médio de produtividade da soja superior a $83 \%$ em relação à testemunha, evidenciando que o controle da ferrugem foi viável, concordando com SoAres et al. (2004). Os autores relataram que o uso de fungicidas para o controle de $P$. pachyrhizi propicia aumento na produtividade de grãos de soja.

A análise dos dados de massa de grão por grão de soja náo revelou interação entre os fatores considerados (Fig. 4), no entanto foi possível perceber diferença significativa quando analisada a média dos regimes hídricos em cada combinação de simulação de chuva.

Plantas que receberam fungicidas e não foram submetidas à simulação de chuva apresentaram incremento significativo

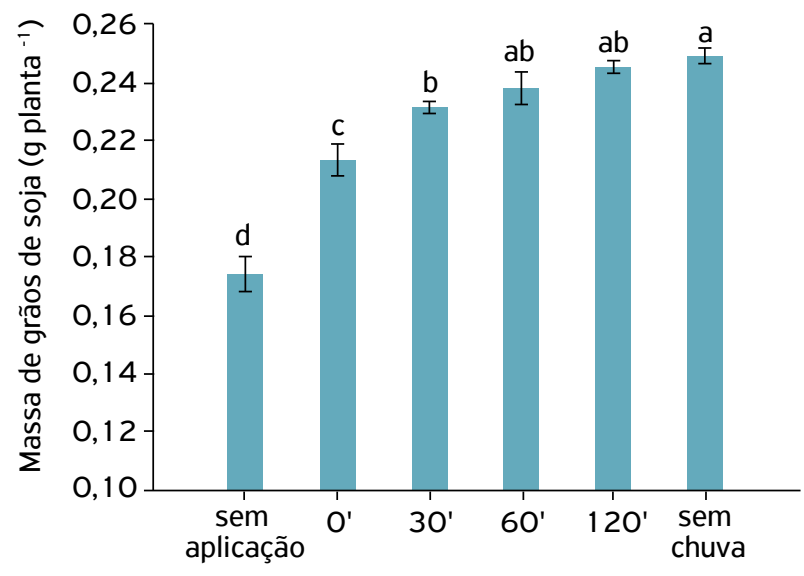

Simulação de chuva (min)

*Letras minúsculas: comparação de intervalos de simulação de chuva na média dos regimes hídricos; médias seguidas pelas mesmas letras minúsculas não diferem estatisticamente entre si pelo teste de Tukey ao nível de $1 \%$ de probabilidade de erro; CV (\%): coeficiente de variação $=4,91$.

Figura 4. Massa de grão de soja ( $g$ grão ${ }^{-1}$ ) na média dos regimes hídricos e intervalos de simulação de chuva após a aplicação. Itaara - RS, 2013. na massa de gráo se comparadas a plantas submetidas à lavagem com chuva simulada. $O$ resultado observado novamente indica o fato de que a simulação de chuva após as aplicaçóes exerce influência negativa na retenção de produtos na folha, resultando em menor residual de controle. Em situação de chuva, há remoção dos ativos ainda não absorvidos e a taxa de penetração do fungicida não é completa, o que reflete no aumento dos valores de severidade de $P$. pachyrhizi, que consequentemente se convertem em menor área fotossinteticamente ativa da folha e na redução na massa de grãos.

De acordo com Silva; Schipanski (2007), os danos observados pelas doenças foliares são decorrentes das lesóes e da necrose do tecido vegetal, que limitam a interceptação da radiação solar e a translocação de fotoassimilados. Assim, as doenças foliares mostram correlação negativa significativa com a massa de grãos. Ou seja, com o aumento da severidade, reduzem a massa de grãos.

Percebe-se que o controle químico em plantas de soja submetidas ao déficit hídrico resultou em incremento residual de controle da doença, assim como em menores valores de severidade.

Por intermédio da condução deste trabalho surge a necessidade de estudos que ilustrem a penetração de fungicidas em plantas sob déficit hídrico, buscando compreensão para o melhor posicionamento de aplicaçóes nessas condiçóes.

\section{CONCLUSÕES}

- A aplicaçáo de fungicida em plantas sob déficit hídrico proporciona o maior número de dias para o aparecimento da primeira pústula;

- A simulação de chuva tem grande efeito na remoção do fungicida independentemente do regime hídrico;

- $\quad$ O controle de P. pachyrhizi em plantas sob déficit hídrico foi eficaz, resultando em incrementos de produtividade.
BONALDO, S.M.; PASCHOLATI, S.F.; ROMEIRO, R.S. Indução de resistência: noções básicas e perspectivas. In: CAVALCANTI, L.S.; DI PIERO, R.M.; CIA, P.; PASCHOLATI, S.F.; RESENDE, M.L.V.; ROMEIRO, R.S. Indução de resistência em plantas a patógenos e insetos. Piracicaba: FEALQ, 2005. p.11-28.

CARVALHO, L.M. Disponibilidade de água, irradiância e homeopatia no crescimento e teor de partenolídeo em Artemísia. 2001. 139f. Tese (Doutorado) - Universidade Federal de Viçosa, Viçosa, 2001.
CAVALCANTI, L.S.; BRUNELLI, K.R.; STANGARLIN, J.R. Aspectos bioquímicos e moleculares da resistência induzida. In: CAVALCANTI, L.S.; DI PIERO, R.M.; CIA, P.; PASCHOLATI, S.F.; RESENDE, M.L.V.; ROMEIRO, R.S. Indução de resistência em plantas a patógenos e insetos. Piracicaba: FEALQ, 2005. p.81-124.

DEBORTOLI, M.P. Efeito do "rainfastness" e adjuvante na aplicação de fungicidas foliares em cultivares de soja. 2008. 57f. Dissertação (Mestrado em Engenharia Agrícola) - Universidade Federal de Santa Maria, Santa Maria, 2008. 
FEHR, W.R.; CAVINESS, C.E. Stages of soybean development. Ames: lowa State University of Science and Technology. 1977. $11 \mathrm{p}$.

FLEXAS, J.; MEDRANO, H. Drought-inhibition of photosynthesis in C3 plants: stomatal e non stomatal limitations revisited. Annals of Botany, v.89, n.2, p.183-189, 2002. DOI: 10.1093/aob/mcfO27

GODOY, C.V.; KOGA, L.J.; CANTERI, M.G. Diagrammatic scale for assessment of soybean rust severity. Fitopatologia Brasileira, v.31, n.1, p.63-68, 2006. DOI: 10.1590/ So $100-41582006000100011$

LEI, W.; TONG, Z.; SHENGYAN, D. Effect of drought and rewatering on photosynthetic physioecological characteristics of soybean. Acta Ecologica Sinica, v.26, n.7, p.2073-2078, 2006.

LENZ, G. Efeito do espectro de gota e idade de trifólios sobre a taxa de absorção de fungicidas em soja. 2010. 73f. Dissertação (Mestrado em Engenharia Agrícola) - Universidade Federal de Santa Maria, Santa Maria, 2010.

LOBATO, A.K.S.; OLIVEIRA NETO, C.F.; COSTA, R.C.L.; SANTOS FILHO, B.G.; CRUZ, F.J.R.; LAUGHINGHOUSE, H.D.I.V. Biochemical and physiological behavior of Vigna unguiculata (L.) Walp. Under water stress during the vegetative phase. Asian Journal of Plant Sciences, v.7, n. 1, p.44-49, 2008. DOI: 10.3923/ajps.2008.44.49

OHASHI, Y.; NAKAYAMA, H.; SANEOKA, H.; FUJITA, K. Effects of drought stress on photosynthetic gas exchange, chlorophyll fluorescence and stem diameter of soybean plants. Biologia Plantarum, v.50, p.138-141, 2006. DOI: 10.1007/s10535-005-0089-3
PAIVA, R.; OLIVEIRA, L.M. Fisiologia e produção vegetal. Lavras: Editora da UFLA, 2006. 104p.

PIMENTEL, C. A relação da planta com a água. Seropédica: EDUR, 2004. $191 \mathrm{p}$.

SANTOS, R.F.; CARLESSO, R. Déficit hídrico e os processos morfológicos e fisiológicos das plantas. Revista Brasileira de Engenharia Agrícola e Ambiental, v.2, n.3, p.287-294, 1998. DOI: 10.1590/1807-1929/agriambi.v2n3p287-294

SILVA, F.A.S.; AZEVEDO, C.A.V. Versão do programa computacional Assistat para o sistema operacional Windows. Revista Brasileira de Produtos Agroindustriais, v.4, n. 1, p.71-78, 2002.

SILVA, O.C.; SCHIPANSKI, C.A. Doenças do milho: o desafio da produtividade com qualidade. In: FANCELLI, A.L.; DOURADO NETO, D. (Eds.). Milho: fatores determinantes da produtividade. Piracicaba: ESALQ/USP/LPV, 2007. p.106-116.

SOARES, R.M.; RUBIN, S.A.L.; WIELEWICKI, A.P.; OZELAME, J.G. Fungicidas no controle da ferrugem asiática (Phakopsora pachyrhizi) e produtividade da soja. Ciência Rural, v.34, n.4, p.1.245-1.247, 2004.

STUHFAUTH, T.; SCHEUERMANN, R.; FOCK, H.P. Light energy dissipation under water stress conditions. Plant Physiology, v.92, v.4, p.1053-1061, 1990.

TAIZ, L.; ZEIGER, E. Fisiologia vegetal. 5.ed. Porto Alegre: Artmed, 2013. p.753-780. 